\title{
Environmental science and technology aesthetics: a Completely Innovative Theoretical Paradigm of Aesthetics
}

\author{
YUE Xiang-yu ${ }^{1}$, YUE You-xi ${ }^{2}$ \\ ${ }^{1}$ School of Management and Engineering, Nanjing University; Nanjing Jiangsu; 210008; PR China \\ ${ }^{2}$ School of Chinese Literature and Journalism, Shandong University of Technology, Zibo city, Shandong province, 255049; PR China
}

\section{Email address:}

yuexiangyu168@gmail.com(YUE Xiang-yu),youxiyue@aliyun.com(YUE You-xi)

\section{To cite this article:}

YUE Xiang-yu, YUE You-xi. Environmental Science and Technology Aesthetics: a Completely Innovative Theoretical Paradigm of Aesthetics. International Journal of Science, Technology and Society. Vol. 1, No. 3, 2013, pp. 57-63. doi: 10.11648/j.ijsts.20130103.11

\begin{abstract}
The environmental science and technology aesthetics" is an innovative and aesthetic concept the author first presented in this article. It is born through the marriage of ecology, aesthetics, science and technology, which is a new interdisciplinary application aesthetic subject that arises with the inspiration of contemporary ecological concepts, environmental ideas, and aesthetic thoughts. It is based on the theories of ecological ontology, ecological ethics and ecological value, and it is the concrete application of environmental aesthetics theory in science and technology area, and the perfect combination of science and technology and environmental aesthetics, and it is the science of the general laws in which science and technology are studied, innovated and developed in accordance with the principles of environmental aesthetics. It, from an aesthetic point of view, with the attitude, viewpoint and method of aesthetics, studies the environmental phenomena, environmental relationships and environmental laws between science and technology and nature, human and society. It fully respects the nature and carries out the science and technology innovation with natural materials and simple and suitable functions and structure. It not only focuses on economic efficiency, but also pays attention to social and environmental benefits. The environmental science and technology aesthetics requires that science and technology could make environment develop sustainably, promote science and technology, nature, human, society to coexist harmoniously, and pursuit that human beings develop harmoniously and always maintain health and vitality in the world and the universe, and it is the unity of environmental aesthetic ideal of human and the development of science and technology innovation. The environmental science and technology aesthetics is the aesthetic sense formed with the value orientation of environmental concept, the human's realization of the environmental value, and the common sense and happy sound of singing that the environmental correlation between science and technology and nature triggered. The environmental science and technology aesthetics is the important theoretical resource that guides the development of modern science and technology. It has great theoretical significance and real practical value for us to surpass the Western traditional dualistic and opposing thinking mode, modern tool reason and anthropocentrism, promote modern science and technology to be environmental and maintain healthy, scientific and ecological development, construct socialist environmental civilization, and build a beautiful China and a beautiful world.
\end{abstract}

Keywords: Environmental Science and Technology Aesthetics, Completely Innovative, Aesthetics, Theoretical Paradigm

Since the industrial revolution, mankind has made great progress in science and technology, creating numerous miracles. The rapid development of science and technology has greatly changed the living circumstances of modern humans, which has brought great benefits to our live and work. Many scholars believe that, however, it is a double-edged sword that it not only brings convenience to mankind, but also hurts humans. It not only has caused enormous damage to the natural environment, but also caused the serious alienation of human nature, resulting in a perplexed and confused state of human spirit and so on. In my opinion, this should not be blamed on science and technology as a tool, while it is the responsibility of humanity itself who use science and technology Therefore, to change this predicament of human beings, the first thing is to adjust the overall survival strategy of humanity, changing the human mind with an active cultural choice to completely alter the current human existence. And this kind of cultural choice is the ecological culture, the core of which is ecological aesthetics. Ecological aesthetics is a panoramic 
system of cultural and scientific concept, covering all the motion system of the universe, like man and nature, man and society, man and man, etc. In technological innovation, only if make a perfect combination with ecological aesthetics, taking an innovative way of environmental science and technology aesthetics, it is able to fundamentally eliminate the alienation phenomenon that science and technology brought to mankind, to thoroughly transform and improve human existence, to truly build a society of socialist ecological civilization, build a beautiful China, and even a beautiful world.

\section{The Concept of Environmental Science and Technology Aesthetics}

It is my first time here to propose an aesthetic concept, environmental science and technology aesthetics. To understand the concept of environmental science and technology aesthetics, we must initially understand the ecological aesthetics. Ecological aesthetics is an interdisciplinary science, based on the ecology and aesthetics. Ecology has broken the western intellectual heritage of subject-object dichotomy with a thought of ecosystem holism, considering the problem that how human as a part of nature develop in harmony with nature in the integrated natural world. Ecological aesthetics is a new form of aesthetic theory, combining ecology and aesthetics. It utilizes the theory of ecology and the method of aesthetic issues, assimilating the important aspects of the ecology into the aesthetic studies, and applying the ecological way of thinking to the field of aesthetics to establish a new type of aesthetic theory that meet the needs of social development. 。 A unique in that is to focus the aesthetic issues on the concept of organic whole. Ecological aesthetic is the entire world, including natural world and human society, as an ecosystem that maintain the ecological balance, and then present an aesthetic significance. That is, human and nature achieve a natural aesthetic state of coordinated development and win-win coopetition.

Environmental science and technology aesthetics mainly refers to the marriage and production between ecology, aesthetics and science technology. It is new interdisciplinary application subject under the enlightenment of the contemporary ecology concept, environmental ideas and aesthetic concepts. It regards the ecological ontology, ecological ethics and ecological value theory as its solid theoretical basis. It is concrete application of the principle of ecological aesthetics theory in the field of scientific and technological innovation. It is the general pattern subject that perfectly combines science and technology and ecological aesthetics which make the study of science and technology proceed to study, innovate and develop according to the principle of ecological aesthetics. It studies the ecological phenomena, ecological relationship and ecological discipline between technology and nature by the attitude viewpoint and method of aesthetics from the perspectives of aesthetics. Ecological aesthetics of science and technology is embodiment of ecological ontology and aesthetics in the field of science and technology. It has considerable start-up and pioneering. Ecological aesthetics of science and technology is not only pay attention to the research of science and technology and natural qualitative, which is the existence of nature. Ecological aesthetics of science and technology reconstructs its philosophical basis in the study of observing science and technology and the nature of the natural inner life. Therefore it belongs to the category of property theory. Ecological aesthetics of science and technology also has more aesthetic meaning, paying attention to observing the science and technology and natural external form of nature, which is the presentation of existence. Therefore it belongs to the category of phenomenology. At the same time, it focuses more on the reality of survival relationship between science and technology and nature, science and technology and people, nature and people. Specifically, is centered on natural ecology and does value orientation and practical reengineering of science and technology. Ecological aesthetics covers three dimensions which human beings appreciate the beauty of science and technology: firstly, truth is beauty, second is kind is beauty and beauty is beauty. It includes three specific ways: Firstly, intellectuality defines a double solution and the science and technology and nature. Then emotion concerns science and technology and nature. Will rebuilds science and technology and nature and so on. Ecological aesthetics is an important theory resources guiding for the development of modern science and technology. It got rid of the traditional western thinking mode of binary opposition, beyond the modern instrumental rationality, beyond anthropocentrism and promotes the ecology of modern science and technology. It is of great significance to keep the healthy development of modern science and technology and scientific benign development, promoting the socialist ecological civilized construction, constructing beautiful China, and even beautiful world.

\section{The Philosophical Foundation of Environmental Science and Technology Aesthetics}

Environmental science and technology aesthetics in philosophy is based on ecological ontology. Ecological theory, a new kind of philosophical theory, is built on the basis of the development of ontological philosophy, and ecological science, which confirm that existence is the existing state and the way of the world, and oppose to looking for the essence and basis outside the real world; it advocates to combine the ancient intuitive holism with achievement of the contemporary ecological science and complexity science to understand the existence as the existence of the entire nature, including human and society. In other words, existence is an organic integration of trinity, consisting of man - society - nature. Ecological ontology 
mainly has three basic characteristics. Firstly, ecological ontology has inherited the overall characteristics of system theory, thinking that ecological existing does not mean the scattered existing of man, society and a variety of other natural things, but mean the existence of the unity. It denies the mechanical concept that ecological existing unity is equal to the simple sum of each part of things and people, based on the affirmation that it is the interaction among man, society and a variety of natural things that composes the ecological existing unity, insisting that the essence of the ecological system has its own specific that is an organic ecological integrity, producing by the non-linear interaction of the internal elements, like man, society and a variety of natural things; special ecosystem exists in a higher level ecosystem environment, influenced by the regulation, condition and development trend of the higher level ecosystem. The overall characteristic of such ecosystem is the qualitative requirement, obtained from the system environment that it exists. Secondly, ecological ontology believes that the existence of man, society and a variety of natural things has the organic character, and they are a unity of organic system. It starts from the concept of ecological science, confirming the organic character of ecological existing of man, society and a variety of natural things. Moreover, it regards the organic character as the ability of self-organization, self-adjustment, and self-selection that bio-system and ecosystem have owned. The whole world has been portrayed as an organic unity that man, society and a variety of natural things mutually penetrate, interact, coordinate and continually evolve. Thirdly, ecological ontology thinks that the ecological being of man, society and a variety of natural things is procedural. From the self-organization theory, existing is truthfully described as the unity of relational, procedural and substantive existing. And the natural ecological process is considered as self-organizing transportation process, adhering to the concept that the links between different levels of physical presence, and different levels of things form in the process of unified transportation. ${ }^{[1](\mathrm{P} 52)}$

Ecological ontology is on the basis of ecological science, and complexity science, which is a summary and distillation of scientific theory. It is a denial to the world view of modern mechanism and the traditional metaphysical ontology, subletting and reverting the ancient organic holism at a higher level. Ecological ontology, including the ontology and natural view in philosophy, is the philosophic basis to establish ecological aesthetics, and the inevitable outcome of time spirit of ecological civilization. Environmental science and technology aesthetics is the specific application of the philosophy of ecological ontology in the field of social practice. Based on the ecological ontology, environmental science and technology aesthetics as a new aesthetic paradigm is a new kind of science that is an organic unity of the humanization of nature and the naturalization of humankind. Environmental science and technology aesthetics aims at the modernity that too much emphasize on the humanization of nature, and the bias of anthropocentrism, which put human above the nature. It also emphasizes the naturalization of humankind, and attaches importance to the natural ecological regulation, regarding human beings as a part of the ecosystem, emphasizing the global existence and evolution of ecosystem; meanwhile, environmental science and technology aesthetics affirms the difference of man and nature, the human's subjectivity, the practical ability and wisdom of people, and confirms that the construction of environmental science and technology aesthetics is based on the practice foundation of the realistic understanding, which mainly rely on the recognition, reflection, coordination and reconstitution of the relation of technology and nature, science and man, man and nature. It is historically inevitable to generate and develop the eco-technology, which is a times calling to eliminating the sever alienation of the relationship between human and nature, caused by the development of science and technology. Also, it is a concrete embodiment of time spirit of the ecological ontology.

\section{The Basis of Ethics of Environmental Science and Technology Aesthetics}

The basis of ethics of environmental science and technology aesthetics is ecological environmental ethics, also known as ecological ethics, which is an ethical viewpoint and theory that advocate extend the moral consideration to nonhuman existence, apart from humans. It is further inheriting, developing and exceeding on the basis of the reflection of the traditional ethics. The core of the theory is to recognize that all kinds of nonhuman existence have the intrinsic value of being independent of human, and the right to life that human must be respect for. Meanwhile, it regards the intrinsic value and right to life (not the interests of human beings) as an ultimate standard to judge if their practice in moral is proper or not, as an important basis to evaluate if their practical behavior is good or evil. ${ }^{[1](\mathrm{P} 105)}$ This is a new ethical idea or value that is revolutionary. The revolutionization and novelty of ecological ethics mainly embodied in its affirmation that a variety of nonhuman existence are independent of human's intrinsic value, and should be respected to have the right to life, which unprecedentedly expanding the moral community or the moral association, providing a new kind of moral basis for us to properly understand the ethical relation among mansociety - natural. ${ }^{[1](\mathrm{P} 105)}$ Ecological ethics has extended the moral community to all the inanimate existence in the nature, breaking the fixation of traditional ethics to human. The view of ethics has been extended from human to a broader nature, making the range of moral community spread from human to nonhuman existence, which expand the scope of ethics, making it realize an unprecedented huge leap. This kind of ethic thought that extends the moral community to all inanimate existence of the nature, is the end of the traditional liberalism and the start of the new liberalism. [1](P105)

Ecological ethics is a kind of ethics which is constantly 
open, requiring that human beings should have a great ecological ethic feeling - the concern for others, the compassion for animals, the cherish for life, and the gratitude to nature. It should encounter with some eternal things, and should relate the meaning of life with a much more grand personal process. Such eternal things and great process (including human life) is the endless nature of life, is the integrity, stability, and beauty of nature, is the growth of heaven and the extension of virtue. We even think that, as a result of the nature or the earth is the originating matrix or parental environment of everything, everything is created by the nature; where there is a positive creativity, then there is a value; therefore, there is no reason to limit the ethics only within the scope of the earth. The universe is the originating matrix of the earth that we occupy, thus we should also cover it into the final ethical realm, beyond the geocentricism or chauvinism, and towards the universal ethics. ${ }^{[2](\mathrm{P} 3)}$

The ecological ethics emphasizes the harmony between man and nature, and the equality of rights. At the same time, it also admits that humans have a particularity that is different from other species of nature, and humans have a characteristic better than other species, which is the capacity of thinking and reason. And the reason of man shows about the cognition of their own behavior, and a certain constraining force of their own behavior. One can control of their own needs to limit himself. Currently, the ecological and environmental problems have sounded a serious warning to mankind. Thus, we should be fully aware of the seriousness of the problems, changing human's attitudes towards nature, and altering our life style to enable the human activity to be adapted to the existence of nature, and to construct a harmonious community between man and nature. ${ }^{[1](\mathrm{P} 165)}$

Ecological ethics is one of the most significant foundations that we set up environmental science and technology aesthetics, which plays an important guiding role in the construction of environmental science and technology aesthetics. Ecological ethics is one of the most significant foundations that we set up environmental science and technology aesthetics, which plays an important guiding role in the construction of environmental science and technology aesthetics. It can help us transcend the anthropocentrism, break through the traditional ways of thinking that the opposition between subject and object, reconstructing reason, subjectivity, recognizing the value of nature, correctly understanding the dialectical unification relations of science technology with human, science technology with nature, human and nature, which provide an important theoretical support for us to protect the ecological environment and construct the ecological aesthetics. Although the ideological change is not obvious before crossing a certain boundary, once the key understanding has been changed, the great changes will immediately sprang up like flood. Our environmental science and technology aesthetics will be to set up with a bang, and humans will gradually step into the real ecological civilization era.

\section{The Basis of Value Theory of Environmental Science and Technology Aesthetics}

The basis of value theory of environmental science and technology aesthetics is the ecological value theory, which is, in eco-ontology era, human's unique and novel basic view and perspective of the value relation of man and nature, and its ecosystem. It is mainly for the modern era of human ontology tools subjective values, and definitely worth the objective existence of the intrinsic value and importance of natural ecological value of the system and re-explain the value of human and ecological relationships. Ecological theory of value from an ecological point of the traditional theory of value to reflect the new natural science evolved on the basis of the new theory of value. It from the value of the academic framework starting on ecosystems, human ecology and in which to explore the value of biological diversity, ecological protection requirements combined with the transformation of existing theory of value or as the value of providing new content. It is the era of human values ontological breakthrough and beyond. Ecological theory of value is mainly philosophical, cultural sense of value theory, discusses the value of nature, the value of specific forms and other issues. It is among the first to admit that is a natural person has the autonomy, independence and initiative on the basis of the special presence, and certainly the value of the natural environment, and certainly the ecological environment and the natural world and its systems have intrinsic value of their own existence and the outer in value, and that they can become the main value and the value object, they both intrinsic and extrinsic value distinction is inherent unity, namely the relationship between the two opposites relationship. It is mainly for the modern era of human ontology tools subjective values, and definitely worth the objective existence of the intrinsic value and importance of natural ecological value of the system and re-explain the value of human and ecological relationships. Ecological theory of value from an ecological point of the traditional theory of value to reflect the new natural science evolved on the basis of the new theory of value. It from the value of the academic framework starting on ecosystems, human ecology and in which to explore the value of biological diversity, ecological protection requirements combined with the transformation of existing theory of value or as the value of providing new content. It is the era of human values ontological breakthrough and beyond. Ecological theory of value is mainly philosophical, cultural sense of value theory, discusses the value of nature, the value of specific forms and other issues. It is among the first to admit that is a natural person has the autonomy, independence and initiative on the basis of the special presence, and certainly the value of the natural environment, and certainly the ecological environment and the natural world and its systems have intrinsic value of their own existence and the outer in value, and that they can become 
the main value and the value object, they both intrinsic and extrinsic value distinction is inherent unity, namely the relationship between the two opposites relationship.

At the same time, it also determines the human on the natural environment responsibility and obligation. Ecological environment value theory core content embodied in the "ecological environmental value" and "the value of the ecological environment" discussion of the connotation of the two concepts. So-called "ecological environmental value", is refers to person with the surrounding ecological environment of the ecological environment system is the inherent value of organic. It is natural ecological environment systems (including people) inherently has given waste, maintains and adjust the balance of the ecological value of life, is maintaining ecological environment system of ecological environment system is stable, complete and beautiful and is the value of itself. It reflects the person with the surrounding ecological environment have source and natural connection. And the so-called "the value of the ecological environment", in the broad sense refers to the ecological environment system and its elements to other elements around it (including people, natural things, mother subsystem, system, etc.) of the survival and development has value of extrinsic value or tools; In a narrow sense, it refers to the ecological environment system and its elements of human survival and development has reflected the extrinsic value or instrumental value, that is just for the other party. "Ecological environmental value" and "the value of the ecological environment" are two concepts with different connotations, is contradictory. However, the relationship between them is unity within.

Ecological values is the complement and development of the universe ontological values, is ontological values of breakthrough and transcendence in humans, it is the ecological aesthetics on production and the formation of the theory of value of science and technology foundation. Traditional philosophy thought, value object can be natural objects, people create wealth, can also be a society, organizations and individuals; Value subject, however, are only a person, group and society, or the only person is qualified to be the value subject. The ontological values of human bias and one-sided development of modern technology, to the "human - nature - society" compound ecosystem of sustainable development bring great obstacles. Therefore, people need to reflect on their values, inheriting and developing traditional Confucian educate "like heaven and earth," the spirit, in their social practice, not only sure one is ecological environment value main body, and emphasize the elements of other ecological environment also can be used as the value of the ecological environment subject; Not only to consider our purpose and values, but also want to consider other living organisms and the ecological environment system, the intrinsic value of the biosphere, from maintenance and promote the survival and development of ecological environment system and earth's biosphere, put its own intrinsic value maximize the ecological systems and biosphere tool translate into value, coexistence and co-prosperity in human and ecological environment system, the coordinated development, on the basis of making its own intrinsic value has been fully and deeply. Subject from the perspective of ecological environment value theory, value of content has already broken through the traditional understanding; believe that the elements of ecological environment system can become ecological environmental value main body. Ecological and environmental value is beyond the anthropocentrism, the human by the master of the world into the ecological environment system of the ordinary one. Human on interest is no longer the center of the world, but in the culture on the human remains the center of the world), the human era turned to ecological ontology by human ontology, fundamentally, is human values the radical transformation, namely ontological values to the ecological environment by human values. The values to value subject goes beyond the traditional values of evaluation main body, thought value subject not only is a person, can also is a person of the other ecological factors. Values of ecological environment not only from the perspective of epistemology, the author affirms the particularity and the independence of the people emphasized the human and the natural ecological environment system value of the unity of opposites relationship, but also from the perspective of ecological ontology, the people and the surrounding ecological environment system is regarded as one of the largest intact ecological environment system, affirmation of the inner of the ecological environment system of organic ecological environment value. And to further emphasize the value of the ecological environment and ecological environment value is dialectical unification. It thinks that ecological environment value and the value of the ecological environment is the objective existence of facts, is the result of the ecological environment system evolution. Every factor of ecological environment system for maintaining ecological environment system of integrity and harmony has made a contribution, therefore have the value of the ecological environment. As human culture phenomenon, ecological environmental value is to surpass ourselves, with the help of people of insight, ecological environmental value relationship analysis of the product, not human judgment and evaluation to the value to suit their own interests, but to incorporate human beings in the ecological environment system of the whole ecological environment system existence value and intrinsic value. Ecological environment value theory is put forward that human reflect on their subject position, forcing people correct their attitude towards the natural ecological environment system and behavior, to protect the interests of the whole ecological environment system, including human, has the special significance. $^{[1](\mathrm{P} 104)}$ The environmental science and technology aesthetics is based on the ecological environment value to build a new aesthetic. 


\section{The Aesthetic Standard of Environmental Science and Technology Aesthetics}

For environmental science and technology aesthetics, one of the most important things to it is its aesthetic standard. Environmental science and technology aesthetics is a kind of brand-new aesthetic standard, which fully embodies on the natural aesthetic. First, the construction and form of the environmental science and technology aesthetic idea, is based on the understanding of eco-technology. Here the so-called environmental science and technology neither refers to the existing pattern of technology, nor refers to the comfortable state of a single person and science technology, but it mainly in the contact of interdependent holistic system of science technology and people, science technology and nature, man and nature. Second, environmental science and technology aesthetic idea is not to isolatedly and mechanically regard the nature of technological beauty from a certain part or the individual of science technology, but to comprehensively regard the technological beauty from the organic whole, and organic links of science technology and life. Third, environmental science and technology aesthetic idea is not only according to the value of human or the extrinsic value of science technology to view the beauty of science technology, but also according to the intrinsic value of science technology and nature to view the beauty of science technology. The beauty of environmental science and technology is not only for man, for science technology itself, but also for the nature. Fourth, environmental science and technology aesthetic idea not only looks the generation of technological beauty from the dimension of nature humanization of science technology, but also looks its generation from the dimension of naturalization of science technology. The evolution of nature is a kind of self-organizing evolution. In the process of self-organizing evolution, the beauty is the aim of natural selection, the direction of natural evolution. Science technology is a part of nature and there is no exception for its evolution. Fifth, environmental science and technology aesthetic idea not only uniformly thinks of harmony from the aspects of science technology and human, science technology and nature, science technology and society, and the interior of science technology, but also from the whole universe, at least from the ordered existence and movement of the life on the entire earth, giving new interpretation and meaning to harmony. Sixth, environmental science and technology aesthetic idea does not regard the artistic beauty as the highest-level beauty, but regards the natural eco-technological beauty as the highest-level and paragon of beauty. In ecological philosophy, the cosmology of eco-ontology means a revolution of philosophical thought; the eco-technology aesthetic of environmental science and technology aesthetics will also fully restore the idea of people, and completely refresh people's lives. This is a
Copernicus type revolution in the field of human thought, and is a great progress of human thought.

The establishment of the category of environmental science and technology beauty is the core of environmental science and technology aesthetics. The aim of it is the eco-technological creation of the human lifestyle and living environment, hoping that the relationship could be mutually harmonious between science technology and man, science technology and nature, man and nature, science technology and society, and the true, the good and the beautiful could be unified, achieving a life realm of free aesthetic technology. Environmental science and technology aesthetics shows the ecological civilization era focus on the reality of science technology and people, science technology and nature, man and nature, science technology and social relations, as well as the ultimate concern it gives to human beings. Such an aesthetic standard, on the standard of eco-technology, is derived from the excavation of the deep wisdom inside the ancient traditional ecological philosophy of China. Also, it references the organically unified concept of the western postmodernism. It is not only the transcendence and challenge to the aesthetic standard of traditional aesthetics, but also is a good chance that once in a blue moon for us to construct the environmental science and technology aesthetics with Chinese characteristics. ${ }^{[3]}$

\section{Conclusion}

In summary, the concept of environmental science and technology aesthetics is an aesthetics concept that I firstly proposed here. It is the marriage of ecology, aesthetics, and science technology, an emerging interdisciplinary subject of new aesthetic application under enlightenment of contemporary ecological concepts, environmental concepts and aesthetic concepts. Such a aesthetics is based on ecological ontology, ecological ethics, and ecological value theory. It is a specific application of theoretical principles of ecological aesthetics in the areas of technological innovation, which means a perfect combination of science technology and ecological aesthetics, as well as a subject that research, innovate and develop in accordance with the general rules of ecological aesthetics. It is the science which investigates the ecological phenomenon, ecological relationships and ecological regulations of science technology and nature, from the aspect of aesthetic with the aesthetic attitude, viewpoint and method. Environmental science and technology aesthetics focuses on the existing relations in reality of science technology and nature, science technology and man, nature and man. In other words, it is centered on the natural ecology, locating the value, and rebuilding the practice on science technology (existing value). Environmental science and technology aesthetics covers three dimensions of the aesthetic standard that humans thing of science technology, namely, taking true as beauty, taking goodness as beauty, taking beauty as beauty. It includes three specific ways that re-understanding science technology and nature by intellectuality, perceiving science technology and 
nature by emotion, and reconstructing science technology and nature by will. For environmental science and technology aesthetics, modern universal human condition but is fine and the hypothetical premise of reality and future, only real the (global) situation of human being history and reality, and in human's ecological existence and ecological development of science and technology as the object of interpretation, realistically can really play the utility and charm of environmental science and technology aesthetics itself. Ecology based on ecological values, to the universe system interaction, modern view of connection, as the starting point, to explore human survival selection and cultural selection. Ecological aesthetics on the basis of the construction of science and technology and in particular on human ecological aesthetic spirit and principles of science and technology, in the past, present and future of human aesthetic activities of science and technology to yourself or criticize or construction of the system point of view, the aesthetic into the real scientific and healthy, and energetic mechanism of human culture system.

Environmental science and technology aesthetics provides theoretical support for the sustainable development of the science technology innovation strategy. Environmental science and technology aesthetics is fully respecting the nature, with natural material and concise applicable function and structure for science technology innovation, focusing on economic benefits, social benefits and ecological benefits. Environmental science and technology aesthetics requires the sustainable development of ecology by modern eco-technology way, promoting the harmony of science technology and man, science technology and nature, man and nature. From a macro perspective of environmental science and technology aesthetics, it is crucial to keep balance of the ecology. It is a way to implement eco-technological design, and show ecological beauty through the modern eco-technology method to realize the harmonious coexistence of human and the nature. The innovation of eco-technology shows to the world that it has used modern eco-technology to achieve the harmonious development of man and nature. Environmental science and technology aesthetics is the inheritance of traditional culture and the respect for local culture, which embodies the cultural ecological aesthetics. Environmental science and technology aesthetics is a science that human in the universe, seek for harmonious development and stay healthy, ad active. Environmental science and technology aesthetics is the unifying of the human's ecological aesthetic ideal and science and technology innovation. It is an aesthetic consciousness, based on the ecological concept of the value orientation, and is made up of the awareness of people on the ecological value and science technology and the natural ecological relevance of empathy and song. Environmental science and technology aesthetics is an important theory guidance for the development of modern science technology of science and technology resources, to transcend the western tradition of the binary mode of thinking, modern instrumental rationality, transcend anthropocentrism, promote the modern science and technology of ecology, maintain its health, the ecological development of science, to promote the socialist ecological civilization construction, the construction of the beautiful Chinese and even the world, has important theoretical guidance meaning and practical value.

\section{Introduction to the Author}

Xiang-yu Yue, male, Han nationality, undergraduate student of Nanjing University, was born in Weifang Shandong province in March, 1992, who is principally good at studying and doing research on electrical information and automation, aesthetics, ecological culture, and so on.

Yue Youxi, male, Han nationality, post-doctor, visiting scholar of Harvard University, was born in Weifang Shandong province in June, 1967, who is a professor, graduate student tutor of the School of Chinese Literature and Journalism, Shandong University of Technology \&. Shandong Research Base for the Soft Sciences of Eco-culture and Recycling Economy, and principally good at teaching and doing research on the literature theories, aesthetics, environmental culture, and so on.

\section{References}

[1] Yue Youxi: "The Environmental Aesthetics", Beijing: People's Publishing House, 2007.

[2] [America] Holmes • Ralston: "Philosophy of Going Toward Wilderness: On Environmental Ethics", New York, 1986.

[3] Yue Youxi: "On the three theoretical foundations to Construct Environmental Aesthetics", "America-China society and culture" (USA) 2010 (1). 